\title{
Synthesis and characterization of zinc oxide nanostructures in biosensor application
}

\begin{abstract}
Nanostructures are defined as any structures or materials with one or more dimension which in the nanometer scale range which is under 100 nanometers. Zinc oxide is a one of many nanomaterials with considerable interest because zinc oxide provides striking advantages in biomedical and clinical sites, thanks to its excellent actions in photonics, electronics, and optics. On account of their large volume surface area ratio, special chemical and physical characteristics, nanosize inorganic compounds showed impressive antibacterial activity at very low concentrations. In order to its outstanding properties, zinc oxide is broadly utilize for varied potential operation for example sun powered cells, optical, bright (UV) lasers, photo-detectors, light-emitting diodes, and electrical instruments. Nonetheless, some few reviews shows that structure, size and uniformity of particles have had a profound impact on zinc oxide nanoparticles, properties and resulted in biosensor application. Homogeneous particle morphology, size and consistency are therefore commonly fundamental necessity for its biomedical appliance. However, zinc oxide nanoparticles morphology is highly depend on their synthesis process and is a multifunctional substance with its own features and versatility. The successful application of zinc oxide in nanodevices and nanobiotechnology are represented by one dimensional (1-D) nanostructures, for example like nanotubes, nanowires, nanorings, nanotetrapods and nanoribbons, tetrapods, nanorods, nanorings, nanoplates, hexagonal, nanospheres, nanoflowers, nanoboxes, tripods, nanotubes, and nanocapses with enhanced biosensor analytical performances.
\end{abstract}

Keywords: Zinc oxide, structures, materials, photonics, tetrapods, nanorods, nanorings, nanoplates, hexagonal
Volume 6 Issue 3 - 2020

\author{
Iman Nurelissa Mohd Ramzuz, Norazreen \\ Zakaria, Zainiharyati Mohd Zain \\ Universiti Teknologi MARA, Malaysia
}

Correspondence: Electrochemical Material and Sensor Research Group, Faculty of Applied Sciences, Universiti Teknologi MARA, 40450 Shah Alam, Selangor, Malaysia, Email zainihar@uitm.edu.my

Received: July 06, 2020 | Published: July 29, 2020

\section{Introduction}

Zinc oxide nanostructures one dimensions have great implements in the fields of biosensors devices. Thus, it is very crucial to recognize the controllable development of this 1-D $\mathrm{ZnO}$ nanostructures and investigating their behavior (Yang, 2010). ${ }^{1}$ On the other hand, not only to noticeable the zinc oxide properties, but also it varies on multiple morphologies, structures and shapes which can be validated by three different type of validation such as Field Emission Scanning Electron Microscopy (FESEM), X-ray Diffractometry (XRD) and Energy Dispersive X-ray Spectroscopy (EDX). ${ }^{1}$ On the other hand, biosensors that act as a platform are not intended to take over traditional analytical methods, but they deliver impressive advantages over conventional techniques when ideal features of a sensing system are achieved. Overall, their speed and low-cost manufacturing make them useful tools for analyzing many samples for primary warnings under certain conditions. In conjunction with biosensor development, impedimetric techniques which act as biosensor transducer have been utilized in order to identify the manufacture of the biosensors and to track the reactivated of proteins or the macromolecule binding occasions of particular binding such as lectins, proteins, receptors, entire cells, nucleic acids, , antibodies or substances linked to antibodies. ${ }^{2}$ Nanohybrids comprised of zinc oxide nanostructures have pulled in huge intrigued since of their strength for progressing catalytic action, surface-to-volume proportions and different other efficacies in a way prevalent to unadulterated zinc oxide nanoparticles. Hence, this work will investigate on immobilization of the E.coli antibody for each of zinc oxide morphologies, that will determine which morphology give the best result in the value of current after the antibody is immobilized. The test also will be validated by electrochemical impedance spectroscopy (EIS) technique. The high sensitivity and selectivity were evaluated through the use of the charge transfer resistance $(\mathrm{RCT})$ the difference $(\triangle \mathrm{RCT})$ before and after the E.coli antibody inactivated on the screen printed carbon electrode (SPCE) zinc oxide structures surfaces.

\section{Morphologies of I-D zinc oxide towards biosensor applications}

Over the last few years, $\mathrm{ZnO}$ nanostructures have a view of attention by reason of common optical, electrical properties relative to their bulk equivalents, and their size-dependent optical as well as their electrical properties, which motivated numerous analyst to examine zinc oxide nanomaterials. Zinc oxide nanomaterials " properties depended heavily on material microstructures such as volume of crystals, morphology that show the ways stacked crystal, aspect ratio, orientation and crystalline thickness. Zinc oxide in nanosized is often examined in many fields, including chemical sensors, biosensors, photocatalysis, solar cells, electrochemical cells, light-emitting diodes, bright (UV) lasers, flat panel displays due to its importance in fundamental science. ${ }^{3}$

\section{Nanotubes}

Due to their lower densities and geometry is 1-dimensional, tubular types of nanosized materials are particularly attractive, which allow quick transportation of electrons for longer distances. In addition, light retention and scattering are extended entirely owing to the broad length-to - diameter proportion of such nanostructures. Thermal evaporation, deposition of microwave plasma, epitaxy of molecular beams, electrodeposition, hydrothermal, template-based, and solution-based technique usually synthesize nano tubes of zinc 
oxide. Most techniques of synthesis are hard and need white heat which is more than $350^{\circ} \mathrm{C}$. The solution-based methods, however, vital for cold in between $25^{\circ} \mathrm{C}$ to $200^{\circ} \mathrm{C}$, moderately basic gear, gentle conditions of response, and scaling potential. The temperature of the reaction, the nature and concentrations of the reactants, the sort of surfactant, $\mathrm{pH}$, and numerous other variables can impact the union of zinc oxide. A contaminant pigment which is degrading Acid Blue 9 in the sludge reactor was placed beneath the ultraviolet light to assess the photocatalytic activity of nanotubes. The synthesized zinc oxide nanotubes photocatalytic activity remains nearly unaltered after being reused thrice, indicating its enhanced steadiness compared to a commercial zinc oxide nanoparticle. ${ }^{4}$ Figure 2.1 below show the SEM pictures of the zinc oxide nanotubes (a), the commonplace cross-sectional see SEM picture of zinc oxide nanotubes (b), and the wide-view SEM pictures of zinc oxide nanotubes (c) and (d) (Figure 1). ${ }^{5}$ In addition, the entails of lower densities and 1-D geometry characteristics, this tubular type of nano-sized materials are particularly attractive which allow quick transportation of electrons for longer distances. Previous study done by Rakshit et $\mathrm{al}^{6}$ has been carried out on the efficacy of zinc oxide nanotubes for glucose sensing using glucose oxidase (GOx) in PBS solution and resulted in response time was founded to be less than 10 seconds, showing a quick electron exchange between zinc oxide nanotubes and GOx structured.

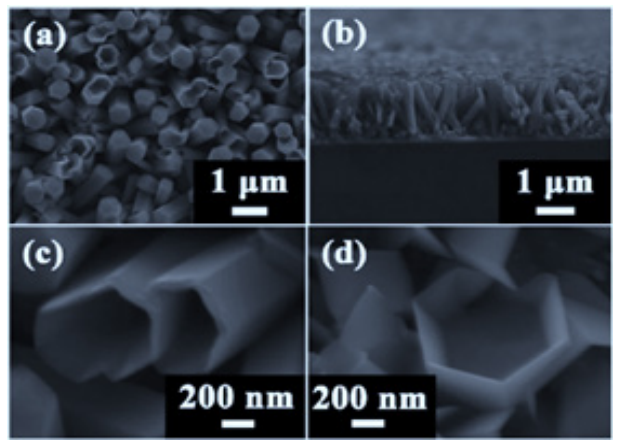

Figure I SEM pictures of the $\mathrm{ZnO}$ nanotubes (A), the commonplace crosssectional see SEM picture of $\mathrm{ZnO}$ nanotubes (B), and the large-view SEM pictures of $\mathrm{ZnO}$ nanotubes (C) and (D). ${ }^{19}$

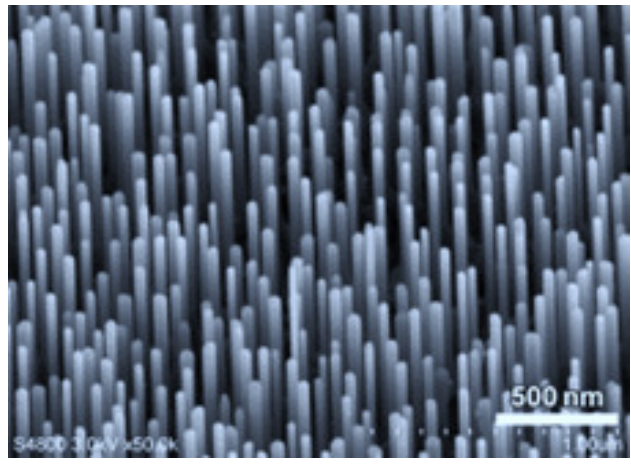

Figure 2 Top and a $30^{\circ}$ view of aligned $\mathrm{ZnO}$ nanowires. ${ }^{\prime \prime}$

\section{Nanowires}

With the impact of quantum confinement and large volumeto-volume ratios, zinc oxide nanowires (NWs) are considerable concern owing to their one-dimensional (1-D) structures. Other than that, 1-D nanostructures provide a coordinate and steady path for fast transportation of electrons. ${ }^{7}$ A zinc oxide NWs regarded as a one dimensional stream under the emission, absorption and transportation of photons, electrons, and holes. Specific configuration systems may have significant trapping effects on photons and carriers, resulting in numerous novel electrical and optical properties for mechanism appliances for example like lasers of nano-meter scale and short wavelength LEDs. Because of their functional operations functioning as nanowires lasers, field emitters, and solar cells, zinc oxide nanowires that vertically aligned on large-area substrates have been extensively studied. Moreover, zinc oxide NWs have appeared exceptional capacities in biosensor application. Zinc oxide NWs have not as it were high surface-to-volume proportions, but moreover high biocompatibility. Hence, it permits the zinc oxide NWs to immobilize chemicals with high effectiveness by means of electrostatic attraction. As a result, zinc oxide NWs have been a common alternative for enzymatic electrochemical detecting of targets such as glucose, ${ }^{8}$ DNA detection ${ }^{9}$ and urea. ${ }^{10}$ Figure 2.2 show that the top at $30^{\circ}$ view of aligned zinc oxide nanowires that allows to the high surface area. ${ }^{11}$

\section{Nanorods}

Zinc oxide nanorods are produced using an anodic aluminum oxide (AAO) a model using electronically initiated sol-gel electrodeposition, it is evolved from nanowires. Zinc oxide nanorodes had a width of around $65 \mathrm{~nm}$ and a dimension of around $10 \mu \mathrm{m}$. Previously, an aqueous method utilized zinc oxide seed layer coated glass substratum to create zinc oxide nanorods. Zinc oxide nanorods had a distance across of around $30 \mathrm{~nm}$ and a dimension of approximately $1 \mu \mathrm{m}$. The vertical modified zinc oxide nanowires and nanorods were defined by X-ray diffraction (XRD) inspection, scanning electron microscopy (SEM), and UV-vis spectrophotometry. ${ }^{12}$ Based on previous research, this non-enzymatic sensor electrodes based on nanocomposite are electrocatalytically active during glucose oxidation, resulting in rapid response, a small detection restrain, and huge sensitiveness.${ }^{13}$ Figure 2.3 show the illustration of the component change $\mathrm{ZnO}$ nanorods to zinc oxide nanotubes and further develop to zinc oxide nanodisks (Figure 3).

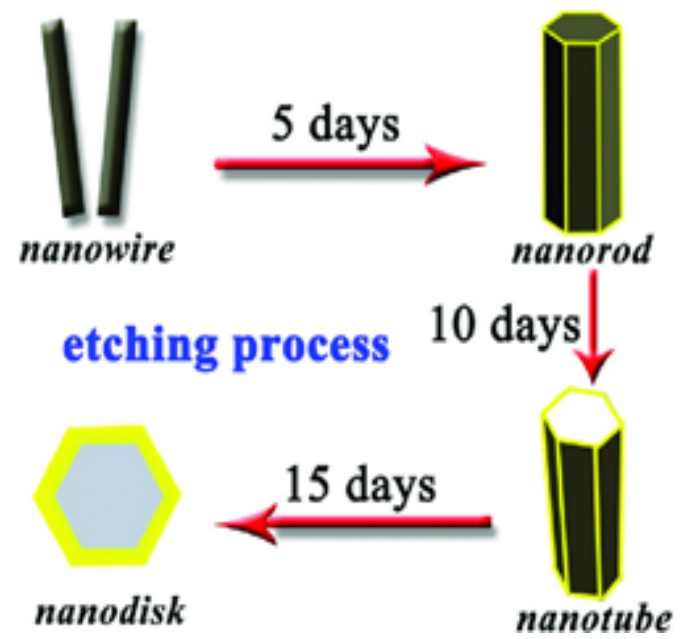

Figure 3 Component of the change of $\mathrm{ZnO}$ nanorods, $\mathrm{ZnO}$ nanotubes, and $\mathrm{ZnO}$ nanodisks.

\section{Nanobelts}

Zinc oxide nanobelts are synthesized utilizing zinc acetic acid derivatives as the main material by chemical precipitation techniques. Observations of SEM suggest that nanobelts lengths range from some 
hundred micrometers to a number of millimeters. The X-ray diffraction pattern affirms the structure of the wurzite ${ }^{14}$ Figure 2.4 below show (a) the XRD design of the synthesized items; (b) a low magnification SEM picture (c) while (d) a high magnification SEM pictures of a Sn-doped zinc oxide nanobelt, uncovering the lean and wide unique shape of the nanobelt. ${ }^{15}$ This nanobelts structure gives a wide surface region to volume proportion of adjusted nanoparticles which is useful for gas detecting applications. Gas sensors manufactured from $400^{\circ} \mathrm{C}$ strengthened nanobelts appeared a reaction of 1.62 when uncovered to $200 \mathrm{ppm}$ of dry carbon monoxide discuss at $400^{\circ} \mathrm{C}$, as characterized by the proportion of resistance some time recently and amid presentation. This shows that zinc oxide nanostructures gotten by warm deterioration of LBZA NBs may give a fetched successful course to tall affectability gas sensors (Figure 4). ${ }^{16}$

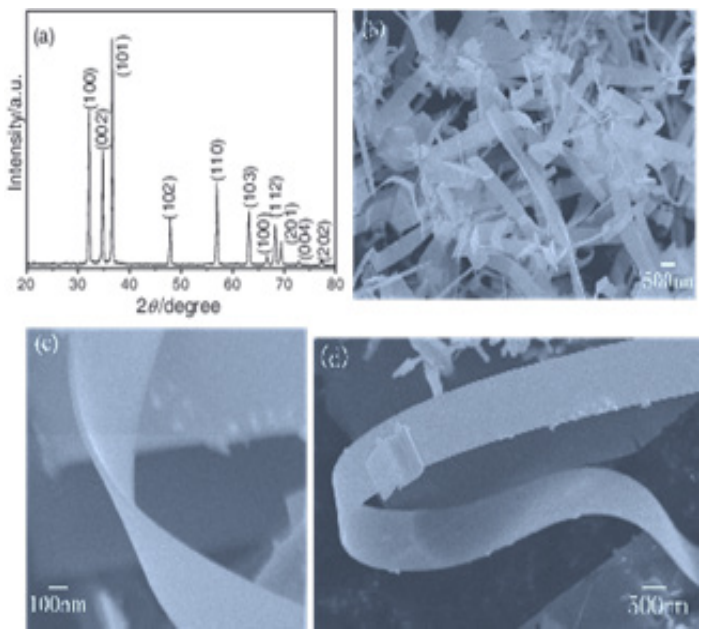

Figure 4 (A) the XRD design of as-synthesized items; (B) a low-magnification SEM picture (C) and (D) a high-magnification SEM pictures of a Sn-doped ZnO nanobelt, uncovering the lean and wide shape characteristics of the nanobelt. ${ }^{15}$

\section{Tetrapods}

Figure 2.5 below reveal a typical zinc oxide tetrapod nanocrystal under scanning electron microscopy (SEM). With a hexagonal transection, each arm is well-faced and consistent in length and distance across. Analysis of X-ray diffraction affirms that the nanocrystals of the zinc oxide tetrapod precipitate into the gem structure of the wurtzite. It is conceivable to obtain command over the measure and morphology of the tetrapod nanocrystals by adjusting development variable such as the substance of $\mathrm{O}_{2}$. Through varying growth conditions, we experienced synthesized uniform tetrapods with span from $200 \mathrm{~nm}$ to $10 \mu \mathrm{m}$ and lateral widths from $50 \mathrm{~nm}$ to $500 \mathrm{~nm} .{ }^{17}$ A study done by Rackauskas et $\mathrm{al}^{18}$ had introduced a novel strategy for the persistent tall abdicate generation of zinc oxide tetrapods (zinc oxide-Ts) with little sizes in order to improve their optical properties and set out novel applications (Figure 5).

\section{Nanoribbons}

Advanced research was carried out before which the structural template for the introduction of $\mathrm{ZnO}$ nanoribbons inside the very small intervening space of the $\mathrm{Zn}_{2} \mathrm{SnO}_{4}$ nanoplates organize the developed on compacted metal wires (CWMWs) and utilize FDSSCs and deactivated photocatalysts as photo anodes to degrade organic dye. A sufficient volume of $\mathrm{ZnO}$ nanoribbons within the $\mathrm{Zn}_{2} \mathrm{SnO}_{4}$ network nanoplates by a straightforward in situ development procedure in place to reinforce interfacial interaction between two parts. Throughout this way, zinc oxide nanoribbons with flexible dimension that can be modified from masses of nanometers to micrometers can act as centers of light dispersion and increment light dispersion. To promote inspection of the presence and conveyance of the zinc oxide nanoribbons, characterization of SEM was conducted to see the morphologies of the respective composite film. The figure below shows a SEM pictures in high-resolution that zinc oxide nanoribbons develop inside the space of the $\mathrm{Zn}_{2} \mathrm{SnO}_{4}$ nanoplate film (Figure 6).

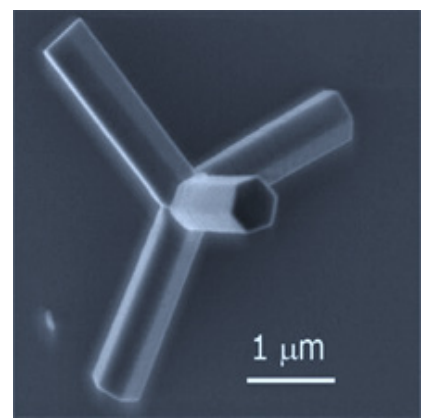

Figure $5 \mathrm{ZnO}$ tetrapod nanocrystal. ${ }^{17}$
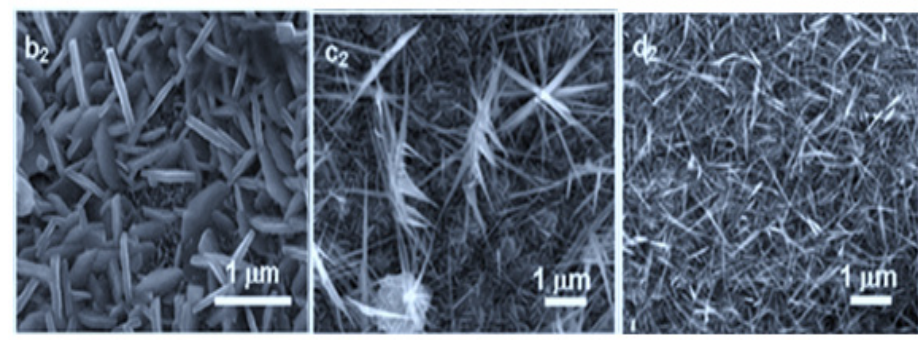

Figure $6 \mathrm{ZnO}$ nanoribbons develop inside the interstices of the $\mathrm{Zn} 2 \mathrm{SnO} 4$ nanoplatefilm (Figure IB 7 IC \& ID2). ${ }^{43}$

\section{Nanorings}

A one-step aqueous process helped by polyvinyl alcohol (PVA) and polyvinylpyrrolidone (PVP) has been created to amalgam of hexagonal zinc oxide nanorings. Electron microscopy scanning (SEM) and X-ray diffractometry (XRD) as appeared in Fig. 2.7 were utilized to distinguish as-prepared zinc oxide nanorings and to infer the conceivable instrument of creation. ${ }^{19}$ The trimethylamine (TMA) detecting execution of the hexagonal zinc oxide nanorings done by Li et $\mathrm{al}^{19}$ showed that the hexagonal zinc oxide nanorings delivered a high reaction from 47 to $100 \mathrm{ppm}$ TMA, a quick reaction not more than $23 \mathrm{~s}$ and $37 \mathrm{~s}$ respectively, wide linearity run from 1 to $200 \mathrm{ppm}$ TMA, hardly distinguishable TMA least concentration (lower than $5 \mathrm{ppm}$ ) and great selectivity to TMA (Figure 7).

\section{Nanocombs}

New research shows that nanostructures of zinc oxide are sufficient for electrochemical biosensors. The chemical utilized to detect glucose oxidase, glucose, was attached to zinc oxide nanocombs, resulting in a biosensor that exhibits larger affinity, good sensitivity, and a strong glucose detection response. This basic process of producing a biosensor based on zinc oxide can be expanded to inactivate certain chemicals and certain bioactive particles on different nanostructures of one dimensions metal oxide and shape flexible electrodes for biosensors studies. ${ }^{20}$ Based on previous research, zinc oxide combs, nanotubes 
and nanorods were used for biosensor enzymes, immunosensors and other sensors of the sort. ${ }^{21}$ Figure 2.8 below show SEM image of a zinc oxide nanocomb (Figure 8 ).

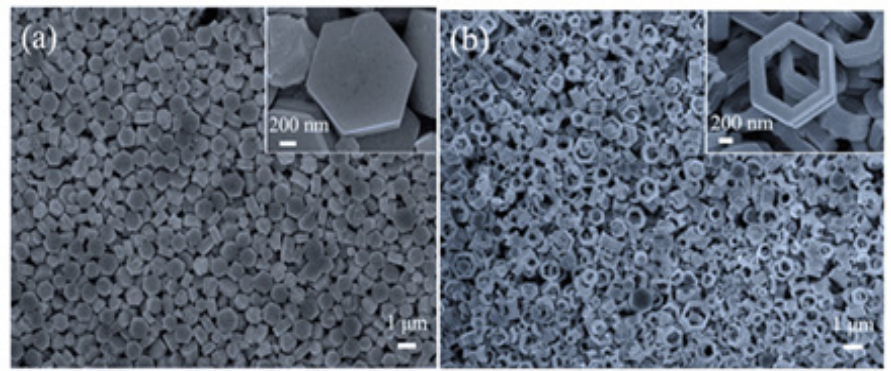

Figure 7 Low- and high-magnification SEM images of (A) nanoplates and (B) nanorings. ${ }^{19}$

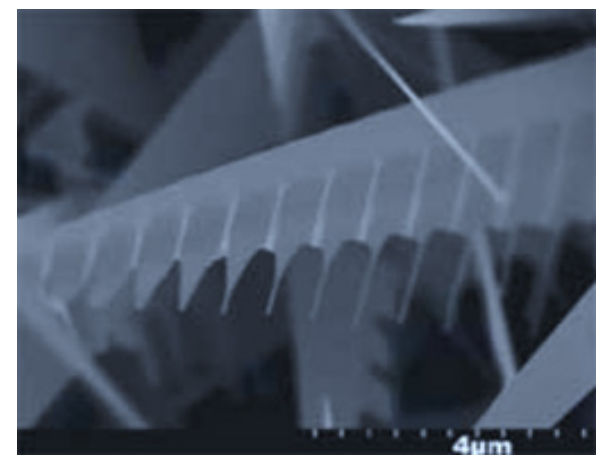

Figure $8 \mathrm{ZnO}$ nanocomb. ${ }^{47}$

\section{Synthesis routes of zinc oxide nanostructures production}

Zinc oxide is a versatile functional product, as stated in the first chapter. With the exception of heteroepitaxial, it includes a wealthy family of nanostructures such as nanorings, nanosprings, nanorods, nanocages, nanotubes, nanobelts and nanowires so that diverse strategies can be utilized to form them as appeared in Figure 2.9. Solgel, microwave-assisted synthesis and colloidal solution are still vital techniques within the union for nanomaterials of semiconductors. These methods share numerous comparative aspects because it is moderately cheap, the quality of the synthesized substance is higher, to prepare the parameters are effortlessly controlled and these strategies are moreover well known.

\section{Synthesis of ZnO nanostructures by utilizing sol-gel method}

Sol-gel procedure is the best approach and is capable of controlling particle size and morphology by continuously tracking the parameters of the reaction. $\mathrm{ZnO}$ nanostructures are amalgamation utilizing sol gel technique utilizing zinc diacetate $\left(\mathrm{Zn}\left(\mathrm{CH}_{3} \mathrm{COO}\right)_{2} \cdot 2 \mathrm{H}_{2} \mathrm{O}\right)$ as a forerunner and ethyl alcohol $\left(\mathrm{CH}_{2} \mathrm{COOH}\right)$ were used as resolvent, while caustic soda $(\mathrm{NaOH})$ and refined water as a medium. An analyzer for XRD, FESEM, EDX and nano-particles characterized $\mathrm{ZnO}$ nanostructures. Figure 2.10 shows the results of the characterization from $\mathrm{EDX}$ indicates that the $\mathrm{ZnO}$ nanostructures have strong sterling with $55.38 \%$ amount of zinc content is and $44.62 \%$ of oxygen content. The XRD outcome spectrum shows predominantly zinc and oxygen peaks, showing nature's crystallinity as shown in Figure 9. The $\mathrm{ZnO}$ nanostructures obtained are homogeneous and similar in volume, which is consistent with the XRD test, which shows fine crystalline. Zinc oxide nanoparticles have been effectively synthesized in the nanosize scale $(81.28-84.98 \mathrm{~nm})$ using sol-gel procedure. The conglomerate of $\mathrm{ZnO}$ nanostructure by sol gel procedure involves the usage of many substance such as zinc diacetate dihydrate $\left(\mathrm{Zn}\left(\mathrm{CH}_{3} \mathrm{COO}\right)_{2} \cdot 2 \mathrm{H}_{2} \mathrm{O}\right)$ as well as caustic soda $(\mathrm{NaOH})$ as well as refined water. As a base, zinc diacetate dihydrate was applied and ethyl alcohol was ply as a testing agent. Refined water was utilized as a dissolvable medium (Figure 9). ${ }^{22}$

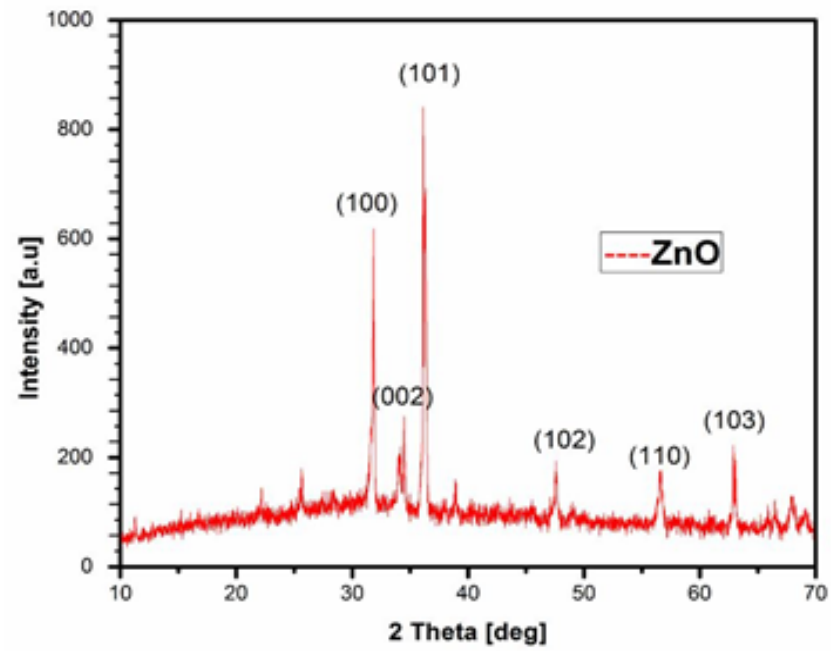

Figure 9 The results of the characterization from EDX FESEM micrographs show that there is a rod-like structure in synthesized $\mathrm{ZnO}{ }^{22}$

\section{Synthesis of zinc oxide nanostructures by using colloidal solution}

Colloidal union is another popular chemical arrangement process with various morphologies and sizes to obtain novel nanomaterials. In order to handle the seeding and growth of products, all storage conditions can be set. The forms of physical and chemical interaction within particles incorporate electrostatic, Vander Waals, ripening Ostwald, and other conceptual theories for example Landau, the theory of Derjaguin, Overbeek (DLVO), and Venvey. Such interactivity can lead to the particles accumulations and subsequent crystallization. Steric equilibrium needs a surfactant to support the colloidal exclusion can avoid colloidal instability. Surfactants work in two mechanisms: to begin with, prevention of particulate relation, and moment, avoidance of persistent molecule nucleation and generation. The forerunners utilized in these blend courses more often than not begin with Zn's fundamental salt, a solvent, and a temperature-like catalyst. In the chosen solvent, the $\mathrm{Zn}$ forerunners must be resolvable in order to provide the requisite $\mathrm{Zn}$ ions for the production of zinc oxide particles. Certain reactives may have been added to substitute zinc oxide with metal positively charge ions such as $\mathrm{Cu}, \mathrm{Ba}, \mathrm{Fe}$ and Co. In addition, surface-active agent may be applied to preserve the product's colloidal stability or affect the growth particle morphology. ${ }^{23}$ Table 1 below summarized the forerunner and solvents utilized in the synthesis of zinc oxide by colloidal solution synthesis.

\section{Synthesis of ZnO nanoparticles utilizing microwaved- assisted method}

Synthesis of microwaves may be a breakthrough in quick 
volumetric warming with low response time and high response speed, selectivity and yield. The ordinary warming technique much longer to achieve the solidification condition by convection, resulting in a thermic slope all through the bulk media and ineffective and unreliable responses that can make genuine crystal growth issues. Ionic conduction and dipolar polarization by dielectric warming are the most important instruments included in microwave warming. Within the theoretical microwave-assisted hydrothermal system, water is utilized as a diamagnetic dissolvable and warm is created by turn, contact and interactions of water particles beneath the impact of a quickly changing rotating electrical field. In fact, the broken up particles within the solutions are always moving beneath the impact of the fluctuating electric field, allowing the nearby temperature to rise steeply due to grinding and collision. A domestic microwave oven of 850 watts $(2.45 \mathrm{GHz})$ was used for the development of zinc oxide nanostructures. It is possible to achieve the high-speed crystallization of zinc oxide nanostructures in just many minutes, otherwise it will take long hours. The high-speed super-saturation and uniform seeding of zinc salts beneath microwave radiation is tested and elective strategies such as the microwave-assisted arrangement substitution, pre-heating, and PEI-based development techniques are too proposed as potential way to stop development. In addition, in incredibly short production time, excellent zinc oxide nanowalls (ZNWs) and zinc oxide nanoflowers (ZNFs) are provided by ammonia treatment. That approach introduced in this research has its claim drawbacks, advantages, and applications for inquire about and improvement. $\mathrm{XRD}, \mathrm{SEM}, \mathrm{PL}$ and EDS are used to investigate the nanostructures morphologies, crystallinity, basic set-up, and radiance properties, separately. ${ }^{24}$ Figure 2.11 show the above and cross-section SEM pictures of ZNRs developed for (a) 2 mins, (b) $5 \mathrm{mins}$, (c) $7 \mathrm{mins}$, (d) $15 \mathrm{mins}$, and (e) ZNRs begin combining into one another to make a film-like surface (Figure 10).

Table I The forerunner and solvents utilized in the synthesis of $\mathrm{ZnO}$ by colloidal solution synthesis

\begin{tabular}{|c|c|c|c|}
\hline Forerunner & Solvent & Stabilizing agent & Reference \\
\hline $\begin{array}{l}\mathrm{Zn}\left(\mathrm{CH}_{3} \mathrm{OO}\right)_{2} 2 \mathrm{H}_{2} \mathrm{O} \text {, sulfo propyl } \\
\text { methacrylatepotassium }\end{array}$ & Ethylene glycol & - & Liua et al \\
\hline $\mathrm{Zn}\left(\mathrm{CH}_{3} \mathrm{OO}\right)_{2} 2 \mathrm{H}_{2} \mathrm{O}$ & Distilled water & Poly(vinyl alcohol) (PVA) & Nagvenkar et al. \\
\hline $\mathrm{Zn}\left(\mathrm{CH}_{3} \mathrm{OO}\right)_{2} 2 \mathrm{H}_{2} \mathrm{O}, \mathrm{LiOH} \cdot \mathrm{H}_{2} \mathrm{O}$ & Ethanol $\left(\mathrm{C}_{2} \mathrm{H}_{5} \mathrm{OH}\right)$ & - & Yuan et al. \\
\hline $\begin{array}{l}\mathrm{Zn}\left(\mathrm{CH}_{3} \mathrm{OO}\right)_{2} 2 \mathrm{H}_{2} \mathrm{O} \\
\text { tetraalkylammonium hydroxide }\end{array}$ & DMSO & $\mathrm{NEt} 4 \mathrm{OH}$ & Panasiuk et al. \\
\hline $\mathrm{Zn}\left(\mathrm{CH}_{3} \mathrm{OO}\right)_{2} 2 \mathrm{H}_{2} \mathrm{O}$ & Ethanol & Triethylamine, diethylamine & Gupta et al. \\
\hline$\left(\mathrm{Zn}\left(\mathrm{NO}_{3}\right)_{2} 6 \mathrm{H}_{2} \mathrm{O}\right), \mathrm{NaOH}$ & Distilled water & $\begin{array}{l}\text { I-Thioglycerol (TG) and } 2 \text { mercaptoethanol } \\
\text { (ME) }\end{array}$ & Hodlur et al. \\
\hline $\mathrm{Zn}\left(\mathrm{CH}_{3} \mathrm{OO}\right)_{2} 2 \mathrm{H}_{2} \mathrm{O}$ & Deionized water & Hexamethyl netetramine & Guo et al. \\
\hline $\mathrm{Zn}\left(\mathrm{CH}_{3} \mathrm{OO}\right)_{2} 2 \mathrm{H}_{2} \mathrm{O}, \mathrm{KOH}$ & Methanol & - & Rahman \\
\hline $\mathrm{Zn}\left(\mathrm{CH}_{3} \mathrm{OO}\right)_{2} 2 \mathrm{H}_{2} \mathrm{O}, \mathrm{KOH}$ & Methanol & PVP & Gutul et al. \\
\hline $\mathrm{Zn}\left(\mathrm{CH}_{3} \mathrm{OO}\right)_{2} 2 \mathrm{H}_{2} \mathrm{O}, \mathrm{KOH}$ & Ethanol & 3-aminopropyltriethoxysilane & Moghaddam et al. \\
\hline $\mathrm{Zn}\left(\mathrm{CH}_{3} \mathrm{OO}\right)_{2} 2 \mathrm{H}_{2} \mathrm{O}, \mathrm{NaOH}$ & Ethyl alcohol & - & Liu et al. \\
\hline $\mathrm{Zn}\left(\mathrm{CH}_{3} \mathrm{OO}\right)_{2} 2 \mathrm{H}_{2} \mathrm{O}$ & Diethylene glycol. & - & Xie et al. \\
\hline $\mathrm{Zn}\left(\mathrm{CH}_{3} \mathrm{OO}\right)_{2} 2 \mathrm{H}_{2} \mathrm{O}$ & Ethanol & $\mathrm{LiOH}$ & Verma et al. ${ }^{14}$ \\
\hline
\end{tabular}

\section{Synthesis of ZnO nanostructures using hydrothermal method}

The forming of zinc oxide (zinc oxide) nanopowders with four distinctive formations for example like nanoparticles, nanorod, nanotubules and nanoplate, hydrothermal line and solution respond strategies is embraced. Mainly in the zinc oxide nanostructures amalgamation, zinc (II) nitrate hexahydrate $\mathrm{Zn}\left(\mathrm{NO}_{3}\right) 2.6 \mathrm{H}_{2} \mathrm{O}$ has been utilize as a forerunner. A hydrothermal technique was employed to synthesize zinc oxide nanoplates and nanorods using $\mathrm{NaOH}$ in the chemical reaction. However, in another chemical respond of $\mathrm{NH} 4 \mathrm{OH}$ and $\mathrm{Zn}\left(\mathrm{NO}_{3}\right)_{2}$ produced zinc oxide nanotubes. Furthermore, zinc oxide nanomaterials were routed in aqueous solution using zinc nitrate precipitation method and ammonium carbonate $(\mathrm{NH} 4)_{2} \mathrm{CO}_{3}$. XRD, TEM and SEM, were utilize to identify the structures, surface morphology of the nanoparticles, and the element components of the $\mathrm{ZnO}$ products manufactured using the above strategies.
These preliminary outcome showed that the prepared zinc oxide nanomaterials have an normal breadth of 30 to $60 \mathrm{~nm}$ while for rodshaped zinc oxide has an standard width of approximately $350 \mathrm{~nm}$ and a length of $3.5 \mathrm{~mm}$ respectively. A flat sheet zinc oxide has a standard density of approximately $40 \mathrm{~nm}$ and a horizontal width of 200 ' $400 \mathrm{~nm}$ while zinc oxide nanotubules have an external breadth of approximately $400 \mathrm{~nm}$ and an internal breadth of approximately $300 \mathrm{~nm}$, approximately $4 \mathrm{~mm}$ in length. The XRD outcome showed that four zinc oxide formation are all root arrangement. The wet chemical technique is found to be very promising in the manufacture of zinc oxide nanocrystallines with different morphologies. ${ }^{3}$ Figure 2.12 show that XRD design of zinc oxide nanoplates, nanoparticles and microrods amalgamation by hydrothermal technique (Figure 11). The EDS X-ray locator tests the relation affluence of the X-rays radiate compared to their vitality. The locator is normally a non-moving parts system with lithium-drifted silicone. This produces a charging beat proportional to the power of the X-ray when the locator is struck by 
an incident X-ray. A preamplifier change the charge beat into a voltage beat which stay corresponding to the X-ray strength. The signal is then transported by voltage to a moving material where the signals are categorize. The vitality is transmitted to a device for show and encourages information analysis for each X-ray event as calculated from the voltage calculation. To estimate the essential composition of the measured volume, the distribution of X-ray vitality versus counts is assessed. ${ }^{25}$ Figure 2.14 shows the EDS peaks of synthesized $\mathrm{ZnO}$ nanostructures (Figure 12). ${ }^{26-50}$

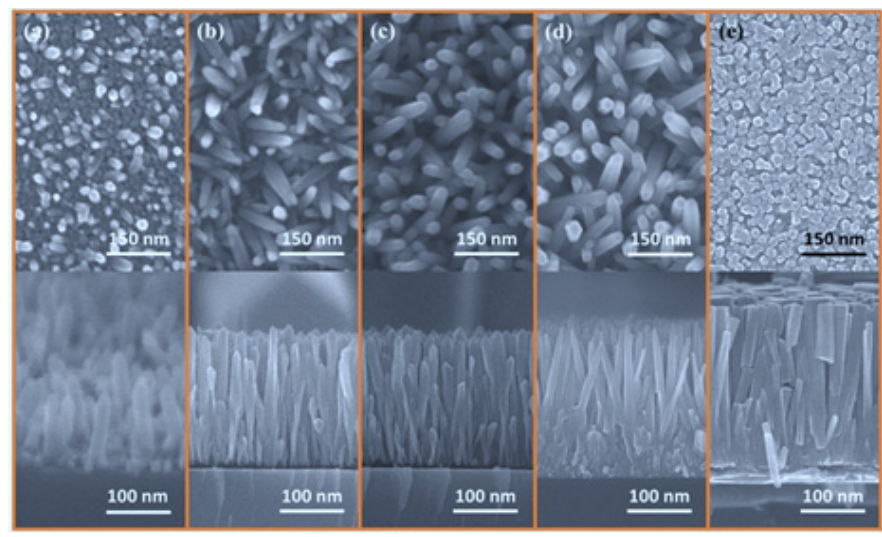

Figure 10 The above and cross-section SEM pictures of ZNRs developed for (A) 2 mins, (B) 5 mins, (C) 7 mins, (D) 15 mins, and (E) ZNRs begin combining into one another to make a film-like surface. ${ }^{24}$

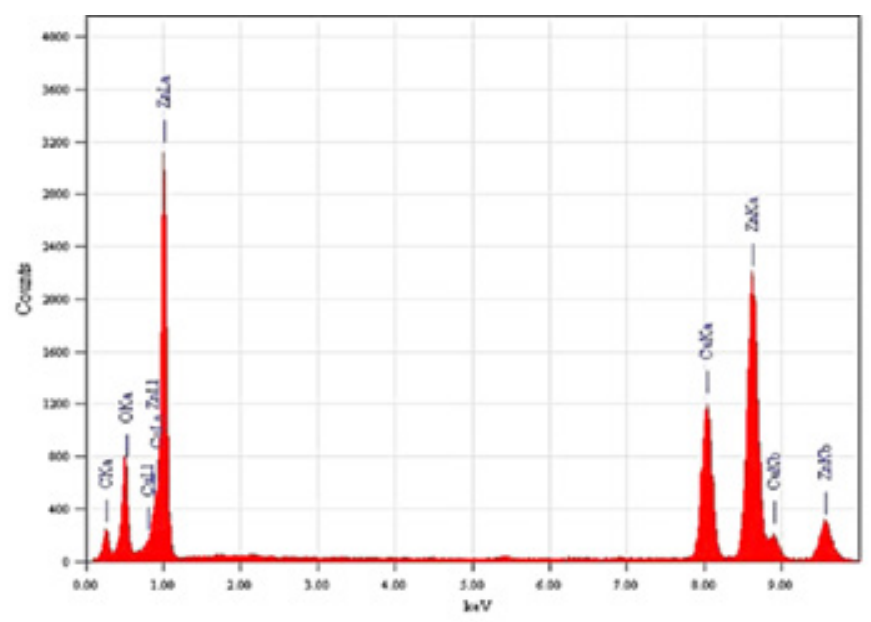

Figure 12 The EDS pattern of synthesized zinc oxide nanoparticles. ${ }^{26}$

\section{Acknowledgments}

None.

\section{Conflicts of interest}

The authors declare that there is no conflict of interest.

\section{References}

1. Yang L. Synthesis and Characterization of $\mathrm{ZnO}$ Nanostructures Linköping: Linköping. University Electronic Press, 2010:107.

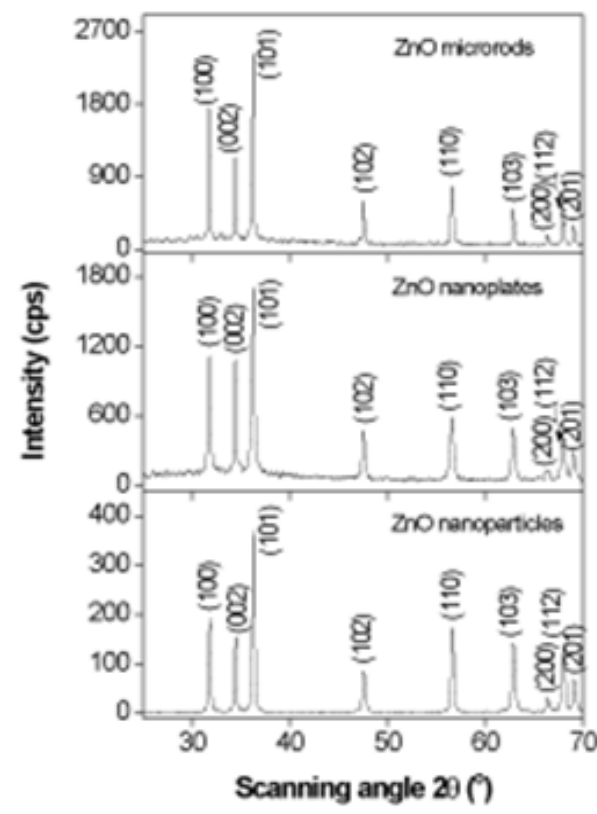

Figure II The XRD design of $\mathrm{ZnO}$ nanoplates, microrods and nanoparticles synthesized by hydrothermal technique. ${ }^{3}$

2. Guan JG, Miao YQ, Zhang QJ. Impedimetric Biosensors. Journal of Bioscience and Bioengineering. 2004;97(4):219-226.

3. Dien ND. Preparation of various morphologies of $\mathrm{ZnO}$ nanostructure through wet chemical methods. Advanced Material Science. 2019;4(1).

4. Samadipakchin P, Mortaheb HR, Zolfaghari A. ZnO nanotubes: Preparation and photocatalytic performance evaluation. Journal of Photochemistry and Photobiology A: Chemistry. 2017;337:91-99.

5. Liu Z. Photoelectrochemical properties and growth mechanism of varied ZnO nanostructures. New Journal of Chemistry. 2017;41(16):79477952.

6. Rakshit T, Mandal S, Mishra P, et al. Optical and Bio-Sensing Characteristics of $\mathrm{ZnO}$ Nanotubes Grown by Hydrothermal Method. Journal of Nanoscience and Nanotechnology. 2012;12(1):308-315.

7. Muhammad Luqman Mohd Napi, Suhana Mohamed Sultan, Razali Ismail, et al. Electrochemical-Based Biosensors on Different Zinc Oxide Nanostructures: A Review. Materials (Basel, Switzerland). 2019;12(18):2985.

8. Hsu CL, Lin JH, Hsu DX, et al. Enhanced non-enzymatic glucose biosensor of $\mathrm{ZnO}$ nanowires via decorated $\mathrm{Pt}$ nanoparticles and illuminated with UV/green light emitting diodes. Sens Actuators $B$. 2017;238:150-159.

9. Mansor NA, Zain ZM, Hamzah HH, et al. Detection of Breast Cancer 1 (BRCA1) gene using an electrochemical DNA biosensor based on immobilized ZnO nanowires. Open J Appl Biosens. 2014;3:9-17.

10. Zhang Y, Nayak TR, Hong H, et al. Biomedical applications of zinc oxide nanomaterials. Curr Mol Med. 2013;13:1633-1645.

11. Zhao $\mathrm{C}$, Chen $\mathrm{A}$, Ji X, et al. Growth of vertically aligned $\mathrm{ZnO}$ nanowire arrays on $\mathrm{ZnO}$ single crystals. Materials Letters. 2015;154:40-43. 
12. Öztürk S, Kılınç N, Taşaltın N, et al. Fabrication of $\mathrm{ZnO}$ nanowires and nanorods. Physica E: Low-dimensional Systems and Nanostructures. 2012;44(6):1062-1065.

13. Tripathy N, Kim DH. Metal oxide modified $\mathrm{ZnO}$ nanomaterials for biosensor applications. Nano Convergence. 2018;5:27.

14. Bhatti HS, Gupta A, Verma NK, et al. Optical characterization of $\mathrm{ZnO}$ nanobelts. Journal of Materials Science: Materials in Electronics. 2006;17(4):281-285.

15. Fang XS, Ye CH, Li Y, et al. Formation and Optical Properties of Thin and Wide Tin-doped ZnO Nanobelts. Chemistry Letters. 2005;34(3):436437.

16. Tarat A, Majithia R, Brown RA, et al. Synthesis of nanocrystalline $\mathrm{ZnO}$ nanobelts via pyrolytic decomposition of zinc acetate nanobelts and their gas sensing behavior. Surf Sci. 2012;606:715-721.

17. Newton MC, Warburton PA. ZnO tetrapod nanocrystals. Materials Today. 2007;10(5):50-54.

18. Rackauskas S, Klimova O, Jiang H, et al. A novel method for continuous synthesis of ZnO tetrapods. J Phys Chem C. 2015;119:16366-16373.

19. Li C. Hexagonal $\mathrm{ZnO}$ nanorings: synthesis, formation mechanism and trimethylamine sensing properties. Rsc Advances. 2015;5(98):8056180567.

20. Michael Berger. A zinc oxide nanocomb biosensor for glucose detection 2006.

21. Xu CX, Yang $\mathrm{C}, \mathrm{Gu} \mathrm{BX}$, et al. Nanostructured $\mathrm{ZnO}$ for biosensing applications. Chinese Science Bulletin. 2013;58(21):2563-2566.

22. Hasnidawani J, Azlina H, Norita H, et al. Synthesis of ZnO Nanostructures Using Sol-Gel Method. Procedia Chemistry. 2016;9:211-216.

23. Garcia JA, Neale ZG, Plaza AA, et al. ZnO Nanostructures Synthesized by Chemical Solutions. Nanostructured Materials - Fabrication to Applications. 2017.

24. Rana AUHS, Kang M, Kim HS. Microwave-assisted Facile and Ultrafast Growth of ZnO Nanostructures and Proposition of Alternative Microwave-assisted Methods to Address Growth Stoppage. Scientific Reports. 2016;6(1).

25. MEE. Energy Dispersive X-Ray Spectroscopy (EDS). 2014.

26. Khalil MI, Maha MAQ, Labis JP, et al. Synthesis and characterization of $\mathrm{ZnO}$ nanoparticles by thermal decomposition of a curcumin zinc complex. Arabian Journal of Chemistry. 2014;7(6):1178-1184.

27. Abdullah KA, Awad S, Zaraket J, et al. Synthesis of ZnO Nanopowders By Using Sol-Gel and Studying Their Structural and Electrical Properties at Different Temperature. Energy Procedia. 2017;119(2017):565-570.

28. Aini BN, Siddiquee S, Ampon K, et al. Development of glucose biosensor based on $\mathrm{ZnO}$ nanoparticles film and glucose oxidaseimmobilized eggshell membrane. Sensing and Bio-Sensing Research. 2015;4(2015):46-56.

29. Akhtar K, Zubair N, Ikram S, et al. Synthesis and characterization of $\mathrm{ZnO}$ nanostructures with varying morphology. Bulletin of Materials Science. 2017;40(3):459-466.

30. Alshehri NA, Lewis AR, Pleydell-Pearce C, et al. Investigation of the growth parameters of hydrothermal $\mathrm{ZnO}$ nanowires for scale up applications. Journal of Saudi Chemical Society. 2018;22(5):538-545.

31. Amin G, Asif MH, Zainelabdin A, et al. Influence of $\mathrm{pH}$, Precursor Concentration, Growth Time, and Temperature on the Morphology of $\mathrm{ZnO}$ Nanostructures Grown by the Hydrothermal Method. Journal of Nanomaterials. 2011:1-9.
32. Bhardwaj R, Bharti A, Singh J, et al. Structural and electronic investigation of $\mathrm{ZnO}$ nanostructures synthesized under different environments. Heliyon. 2018;4(4):e00594.

33. Bunaciu AA, Udristioiu EG, Aboul-Enein HY. X-ray diffraction: instrumentation and applications. Crit Rev Anal Chem. 2015;45(4):289299.

34. Cui J. Zinc oxide nanowires. Materials Characterization. 2012;64:4352 .

35. Djurišić AB, Chen $\mathrm{X}$, Leung $\mathrm{YH}$, et al. $\mathrm{ZnO}$ nanostructures: growth, properties and applications. Journal of Materials Chemistry. 2012;22(14):6526.

36. Ekthammathat $\mathrm{N}$, Thongtem $\mathrm{S}$, Thongtem $\mathrm{T}$, et al. Characterization and antibacterial activity of nanostructured $\mathrm{ZnO}$ thin films synthesized through a hydrothermal method. Powder Technology. 2014;254:199205.

37. Farhadi-Khouzani M, Fereshteh Z, Loghman-Estarki MR, et al. Different morphologies of $\mathrm{ZnO}$ nanostructures via polymeric complex sol-gel method: synthesis and characterization. J Sol-Gel Sci Technol. 2012;64:193-199.

38. Gerbreders V, Krasovska M, Sledevskis E, et al. Hydrothermal synthesis of $\mathrm{ZnO}$ nanostructures with controllable morphology change. CrystEngComm. 2020;22(8):1346-1358.

39. Ibrahim K, Khalid MH, Eisa MH, et al. Comparative Study of AFM and FESEM for Imaging the Single Cell of Escherichia Coli Bacteria. Journal of Nano Research. 2015;34:61-66.

40. Jan Ddík, Marcela Janovcová, Hana Dejmková, et al. Utilization of unmodified Screen-Printed Carbon Electrodes in Electoanalysis of Organic Compounds. 2011.

41. Jiang J, Pi J, Cai J. The Advancing of Zinc Oxide Nanoparticles for Biomedical Applications. Bioinorganic Chemistry and Applications. 2018;2018:1-18.

42. Kathalingam A, Park HC, Kim SD, et al. Synthesis of ZnO nanorods using different precursor solutions and their two terminal device characterization. Journal of Materials Science: Materials in Electronics. 2015;6(8):5724-5734

43. Li Z, Bi D, Zhao Y, et al. In situ growth of zinc oxide nanoribbons within the interstices of a zinc stannate nanoplates network on compacted woven metal wires and their enhanced solar energy application. Electrochimica Acta. 2018;262:124-134.

44. Musić S, Dragčević D, Popović S, et al. Precipitation of ZnO particles and their properties. Mater Lett. 2005:2388-2393.

45. Khwaja Salahuddin Siddiqi, Aziz Ur Rahman, Tajuddin, et al. Properties of Zinc Oxide Nanoparticles and Their Activity Against Microbes. Nanoscale Res Lett. 2018;13(1):141.

46. UPV. Field Emission Scanning Electron Microscopy: Electron Microscopy Service. 2017.

47. Wang JX, Sun XW, Wei A, et al. Zinc oxide nanocomb biosensor for glucose detection. Applied Physics Letters. 2006;88(23):233106.

48. Wang Y, Ye Z, Ying Y. New trends in impedimetric biosensors for the detection of foodborne pathogenic bacteria. Sensors (Basel). 2012;12(3):3449-3471.

49. Wang ZL. Zinc oxide nanostructures: growth, properties and applications. Journal of Physics: Condensed Matter. 2004;16(25):R829-R858.

50. Zhang Y, Ram MK, Stefanakos EK, et al. Synthesis, Characterization, and Applications of ZnO Nanowires. Journal of Nanomaterials. 2012:122. 